\title{
HuValue: a tool to support design students in considering human values in their design
}

\author{
Shadi Kheirandish ${ }^{1,2}$. Mathias Funk ${ }^{1}$. Stephan Wensveen ${ }^{1} \cdot$ Maarten Verkerk $^{3}$. \\ Matthias Rauterberg ${ }^{1}$
}

Accepted: 22 May 2019 / Published online: 28 May 2019

(c) The Author(s) 2019

\begin{abstract}
Human values play an integral role in any design that aims to improve the quality of human life. However, only a few design approaches concentrate on human values in their design, and there is even very little agreement between them in identifying human values. Considering this, we created a design tool based on a comprehensive value framework to support designers' addressing human values in their designs. This tool intends to raise designers' awareness about human values and provide tangible materials to facilitate the use of selected values within the design process. This article investigated whether this tool is applicable and effective to be used in design education. A quasi-experimental study with design students showed that the project groups who were supported with this tool addressed significantly stronger human values in their design concepts compared to the control groups. Results of the evaluation indicated that the tool is not only applicable in a design process but is also effective at enriching design concepts with human values.
\end{abstract}

Keywords Design education · Design process · Design tools · Evaluation · Human values

Shadi Kheirandish

S.Kheirandish@tue.nl

Mathias Funk

M.Funk@tue.nl

Stephan Wensveen

S.A.G.Wensveen@tue.nl

Maarten Verkerk

m.verkerk@maastrichtuniversity.nl

Matthias Rauterberg

G.W.M.Rauterberg@tue.nl

1 Department of Industrial Design, Eindhoven University of Technology, Eindhoven,

The Netherlands

2 Department of Industrial Design, Alzahra University, Tehran, Iran

3 Faculty of Arts and Social Sciences, Maastricht University, Maastricht, The Netherlands 


\section{Introduction}

Nowadays, life without technology is hardly imaginable. In this era, technology is interwoven with all aspects of life, and people perceive the world via products. Besides the many papers in the literature that have stated that products influence human behaviour (e.g., Dorrestijn 2012; Lockton 2013; Stanton and Baber 1998), products are not neutral instruments but "active mediators in the relation between humans and reality" (Verbeek 2005, p. 235). Verbeek (2005) argues that products play a mediating role between human beings and the world, anticipating the future in that they co-shape the existence and experience of people-and consequently their lifestyle.

As products are not self-formed phenomena, emphasising their role in human life brings to light the responsibility of designers. Supporting this statement, Verbeek recalls the moral responsibility of designers in shaping the future (2005, p. 234). Although design in its origin aims "at changing existing situations into preferred ones" (Simon 1996, p. 111), there is very little agreement on what a 'preferred/better situation' means or how to achieve one.

According to Rokeach (1973, p. 5), value is "an enduring belief that a specific mode of conduct or end-state of existence is personally or socially preferable to an opposite or converse mode of conduct or end-state of existence". Human values guide human actions and behaviour in daily situations. They give expression to basic human needs. Values have a strong motivational component. They refer to desirable goals. Values serve as standards and criteria, and value systems are general plans employed to resolve conflicts and make decisions. Indeed, the employment of values as standards is a fundamental difference between being human and nonhuman (Rokeach 1973).

Indeed, in technology and design education literature, the importance of values is well established (e.g., Barlex 1993; Breckon 1998; Coles and Norman 2005; Conway 1994; Conway and Riggs 1994; Dakers 2005; de Vries 2005; Elshof 2005; Holdsworth and Conway 1999; Järvinen and Rasinen 2015; Layton 1991; Martin 2002; McLaren 1997; Middleton 2005; Pavlova 2005, 2009; Prime 1993; Rekus 1991; Riggs and Conway 1991; Tungaraza and Sutherland 2005). The studies mentioned in this list mainly target school educators and emphasise the significance of addressing values in technology education (as a means of improving the quality of life for all). Considering pupils as future citizens with influential professions, these studies note the responsibility of teachers for raising pupils' awareness about different types of values in life (Conway 1994). They emphasise the role of values for decision-making, value judgements and evaluation in design as a complex intellectual activity (Pavlova 2009). In this respect, they acknowledge the need for developing a new values classification (Coles and Norman 2005) and as well, practical ways to uncover, explicate and discuss the values embedded within technologies in classrooms (McLaren 1997; Middleton 2005). However, the reviewed studies mostly focused on addressing values in developing curriculum and pedagogy rather than creating practical and tangible tools for design students. Therefore, in this paper, after reviewing the main studies about human values in design, we will introduce a human value-based tool, applicable in design education for training design students to address human values in their design. 


\section{Human values in design}

What does the word 'value' bring to mind? In other words, what is the meaning of 'value'? The term 'value' is not so easy to define and, further, is usually used differently in various contexts. From an economic standpoint, it is about the price of things while, in other contexts (e.g., social or political), it is used to connote the importance of things. Although these two definitions look similar at first glance, they reveal an ambiguity: The Oxford Dictionary, for instance, explains value in three ways: "(1) how much something is worth in money or other goods for which it can be exchanged. (2) How much something is worth compared with its price. (3) The quality of being useful or important" (The Oxford Dictionary, 2018). It also states that values are: “(4) beliefs about what is right and wrong and what is important in life" (The Oxford Dictionary, 2018).

Within the design discipline, all different aspects of value seem relevant and applicable, since design deals with both objects and humans as well as the interaction between them. In fact, "design is beset with values" (Steen and van de Poel 2012, p. 70), and applying values in design can be seen not only as an exchange-not only a meaningful difference and experience, but also an enduring belief (Boztepe 2003). However, these different applications have not received equal attention from designers. Indeed, a search for value in design shows that there are many design approaches and practices that focus on value as the quality of being useful and important', for instance, User-Value-Based Product Adaption (Boztepe 2007a), Value Based Design (2018), Value-based Design Software Engineering (Biffl et al. 2006), Value-Driven Design (Collopy and Hollingsworth 2011), Value-Centric Design (O'Neill et al. 2010), and High Value Design (Nackmayr et al. 2016). However, as results of our literature review indicate, very few designers to date have paid attention to 'human value' as 'what is important for people in life' at a necessarily abstract level. Nevertheless, this attention is increasing (Friedman and Kahn 2003; Halloran et al. 2009; Iversen and Leong 2012).

To investigate human values in design, we reviewed the related literature and searched for design approaches that focus on human values. In our literature study, we found three independent design approaches: (a) value sensitive design (VSD); (b) value-led participatory design (VPD); and (c) value-centred design (VCD), that all aim at addressing human values in design. However, besides these independent design approaches, there are several institutes such as the Values in Design Council (Knobel and Bowker 2011) and the Delft Design for Values (TUDelft Design for Values 2018) — suites of projects that refrain from suggesting any independent approach to human values. We also found some authors (e.g., Cummings 2006; Oosterlaken 2015) who have applied one of these approaches, some who (e.g., Kujala and Väänänen-Vainio-Mattila 2008; Manders-Huits 2011) have written an overview or critique of them, some (e.g., Halloran et al. 2009) who have worked with values in design without following any of those specific approaches or establishing a new method and, finally, some scholars (e.g., Onselen and Valkenburg 2015; Ross 2008) who have not followed any of these approaches but applied one of the existing approaches in the social sciences. We also found some scholars (e.g., Detweiler 2016) who extended the value list of VSD in pursuing their own research. 


\section{Value sensitive design (VSD)}

Value sensitive design is a "theoretically grounded approach to the design of technology that accounts for human values in a principled and comprehensive manner throughout the design process" (Friedman et al. 2017, p. 64). This approach was originally proposed by Friedman and her colleagues in the 1990s and was intended to be applied to human-computer interaction and information science. In this approach, value is defined as "what a person or group of people consider important in life" (Friedman et al. 2013, p. 56). They provide a list of $13^{1}$ human values with ethical import as is often implicated in system design: (1) human welfare, (2) ownership and property, (3) privacy, (4) freedom from bias, (5) universal usability, (6) trust, (7) autonomy, (8) informed consent, (9) accountability, (10) courtesy, (11) identity, (12) calmness, and (13) environmental sustainability (Friedman et al. 2013). This list does not intend to be complete but presents a list of "frequently implicated values" to suggest values that should be considered in the investigation.

The notion of VSD, based on an iterative methodology, integrates conceptual, empirical, and technical investigations. As Friedman described it, conceptual investigations "involve philosophically informed analyses of the central construct and issues under investigation", empirical investigation "involves social-scientific research on understandings, contexts, and experiences of people affected by technological designs", and technical investigations "involve analysing current technical mechanisms and designs to assess how well they support particular values, and, conversely, identifying values, and then identifying and/or developing technical mechanisms and designs that can support those values" (Friedman and Kahn 2003, p. 1187).

\section{Value-led participatory design (VPD)}

Participatory Design (PD) is a design approach that involves all stakeholders in the design process. With a Scandinavian tradition and high respect for democracy, it stresses the importance of working with values in the system development process to respect people's democratic rights (Iversen et al. 2012a, b). In this case, Iversen (a Danish interaction designer) and his colleagues argued that an effective way to do this was "to elevate values to the fore of Participatory Design (PD) inquiries, and to engage with values as the engine that drives the design activities" (Iversen and Leong 2012, p. 468). In VPD enquiry, values are defined as "enduring beliefs that we hold concerning desirable modes of conduct or end-state of existence in different situations, societies, and cultural contexts" (Leong and Iversen 2015, p. 315). In this definition, they employed the research of social scientists such as Rokeach (1973). However, they did not use any existing list of values. In fact, they rejected using a set or fixed list of values since, as they argued, in their work "values are emergent and can vary from one project to another" (Iversen et al. 2010, p. 92). They thus attempt to find local expressions of values during the design process. In accordance with their roots, they focus on the value of workplace democracy, quality of work life, and designing for skilled workers (Iversen et al. 2012b). VPD inquiry consists of a recursive three-phase process: the emergence, development, and grounding of values, trying to bring not only users' and stakeholders' values, but also designers' values to the PD processfrom early analysis to the final product (Leong and Iversen 2015).

\footnotetext{
${ }^{1}$ This list, in earlier publications (Friedman and Kahn 2003; Cummings 2006), excluded 'courtesy', thus presenting 12 human values.
} 
Table 1 Different ways of identifying human values by the three design approaches of VSD, VPD, and VCD

\begin{tabular}{llll}
\hline Design approach & List of values & $\begin{array}{l}\text { Number of } \\
\text { values }\end{array}$ & $\begin{array}{l}\text { Validation } \\
\text { of the list }\end{array}$ \\
\hline VSD & Yes & 13 & No \\
VPD & No & - & - \\
VCD & No & - & - \\
\hline
\end{tabular}

\section{Value-centred design (VCD)}

Cockton (2005) pointed out that human-computer interaction (HCI) was system-centred up to the 1970s, user-centred in the 1980s, and context-centred in the 1990s. He argued that these human-computer interaction approaches, while necessary, are not sufficient. He believed that a value-centred focus should be the fourth leg "to create a stable structure for HCI" (Cockton 2005, p. 1292). According to him, HCI needs to focus on design which is defined as "intent to create value" (p. 1292). In addition, he noted that values are what users really want: designers do not define value but talk to people about it (Cockton 2004).

To achieve this goal, Cockton (2005) designed a value-centred framework and added four processes to the existing development methodologies: opportunity identification, design, evaluation, and iteration. In the first process, the intended value is specified for a digital product by the means of chat interviews with users. Later, however, to avoid "confusion (especially 'value' vs 'values') and distracting associations of the word "value", (Cockton 2006, p. 165), he changed 'value-centred' to 'worth-centred'. He noted that value-centred design - in other words, worth-centred design—does not have any roots in morality but it is "a logical consequence of usability and contextual approaches", with a focus on the 'worthwhile' in which 'worth' is a motivator "to buy, learn, use or recommend an interactive product" (pp. 167-168).

\section{Problem statement and research goal}

The reviewed literature shows that, despite the significance of human values in everyday life and consequently in design, they mostly remain implicit and unarticulated in design projects (Steen and van de Poel 2012). Only a few design approaches concentrate on human values and aim to address them in their design; further there is very little agreement among them in identifying those values (Boztepe 2007b). In this respect, the lack of an established and accepted fundamental grounding (Boztepe 2003) and a comprehensive list of values (Borning and Muller 2012) can be considered as an unresolved issue. Our justification regarding this need can be summarised as follows (see Table 1).

The three design approaches (VSD, VPD, and VCD) have different ways of identifying values. VSD is the only design approach that introduced a value list for design. However, this list is neither general nor comprehensive. In other words, the authors (Friedman et al. 2013) proposed only 13 moral values that are often implicated in system design, but they are not representative of the various types of human values that exist. This list looks arbitrarily chosen, and Friedman and her colleagues did not try to validate their proposed value list. In contrast, VPD (Iversen et al. 2010) and VCD (Cockton 2005) refused to use a fixed list since, the proponents argued, every project is different. This means they left the whole task of identifying values for designers and assumed that the latter possess a 
sufficient understanding of the concept of human value, and have a broad perspective on its various dimensions, to accomplish this. Although they already recognise that "the kind of values that emerge depends on how designer orchestrate the design process" (Iversen et al. 2012a, p. 95), VCD and VPD did not suggest any method to raise designer's awareness about human values; rather, they were left to find their own way in the massive amount of available information about the subject.

Since the term 'value' is widely used for different purposes in various disciplines, and there is no comprehensive value framework for design, we considered the need for guidance for designers. We derived a general list of values to cover diverse views and, as well, a well-classified framework to summarise the list in a brief, understandable and applicable model. This serves to both simplify thinking about the values and enable discussion of them. In this respect, a holistic view of the values of different aspects of human life is important for design, since improving the quality of human life is the aim of designand this improvement is related to progress in all aspects of life (Saariluoma et al. 2016). Accordingly, we designed a tool, using the comprehensive value framework of Kheirandish (2018). This tool aims to simplify the use of the value framework in the course of design to bring human values consciously and explicitly into design discussions and practices. The core assumption for developing such a tool is that raising designers' awareness about human values and facilitating their application within the design process would serve to increase the impact of such values across the design itself. Although the HuValue tool-as it is termed-was developed to help both design students and professionals, in this article, we investigate whether this tool is applicable and effective to be used in design education. Indeed, training design students to use the tool per se is a way of bringing the HuValue perspective into real practice (given that design students plan to become professionals in the near future). As related studies in design and technology education thus far mostly have focused on school education (see the list of the reviewed studies in the Introduction), in our study, we targeted first-year design students in an engineering-focused university. In this programme, the first year focuses on building awareness of various areas of expertise related to the field of industrial design. We selected first-year students, as they are expected to initiate a design project for first time and are likely open to new approaches and careful about each step in their design process.

\section{The HuValue tool}

Our tool, called HuValue, was designed in the form of a card-based design tool (Figs. 1, $2,3)$. This form was selected for the design tool since cards are low-tech, tangible, and approachable design materials that recently have become popular (Lucero et al. 2016). Generally, cards have been widely used by designers to visualise the design process and make it less abstract (Wölfel and Merritt 2013). Card-based design tools are an effective medium to bridge the gap between theories and practice, to present theoretical constructs, and to make the design practice playful and engaging. They can be a source of inspiration and facilitate creative dialogue and shared understanding (Mora et al. 2016). In fact, they are beneficial for communicating between design teams and also with users (Wölfel and Merritt 2013). Additionally, they can be used for evaluating and rating ideas (Mora et al. 2016). Design cards are capable of supporting different phases of a design process as they can be used differently in each situation (Lucero et al. 2016). 


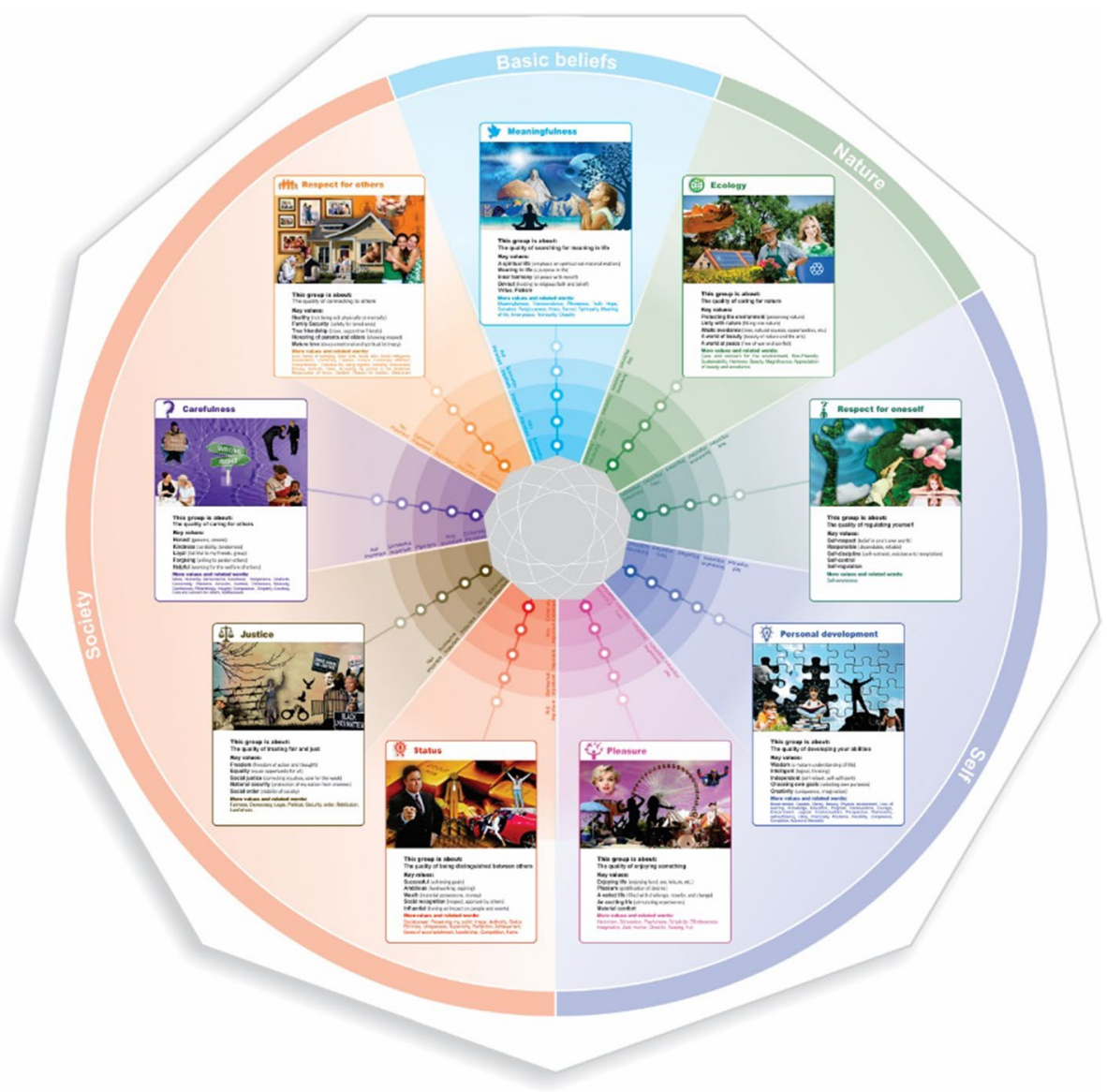

Fig. 1 Value wheel (Size: A2), with nine value clusters and five-point Likert-type scales

Fig. 2 An example of value words (Size: $5 \times 7 \mathrm{~cm}$ ), two-sided cards with a value word on the front and its relevant value group at the back

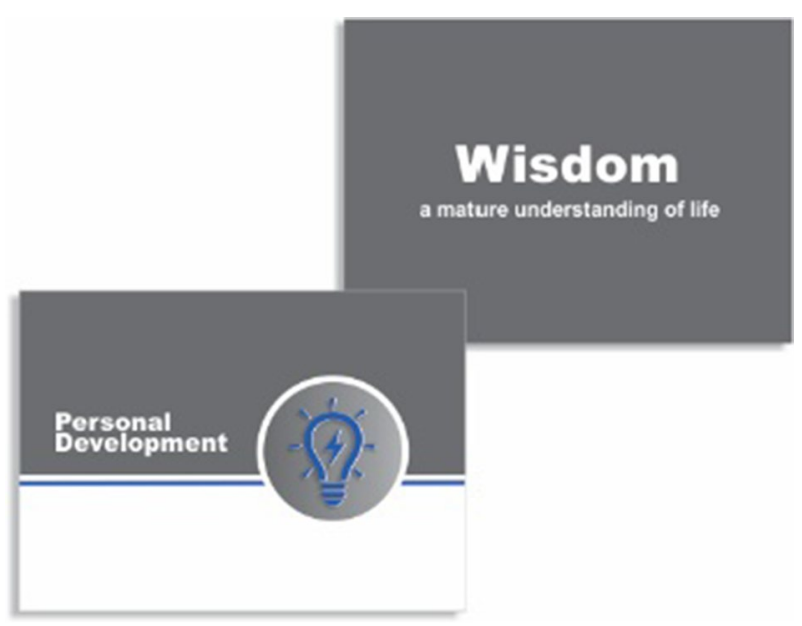



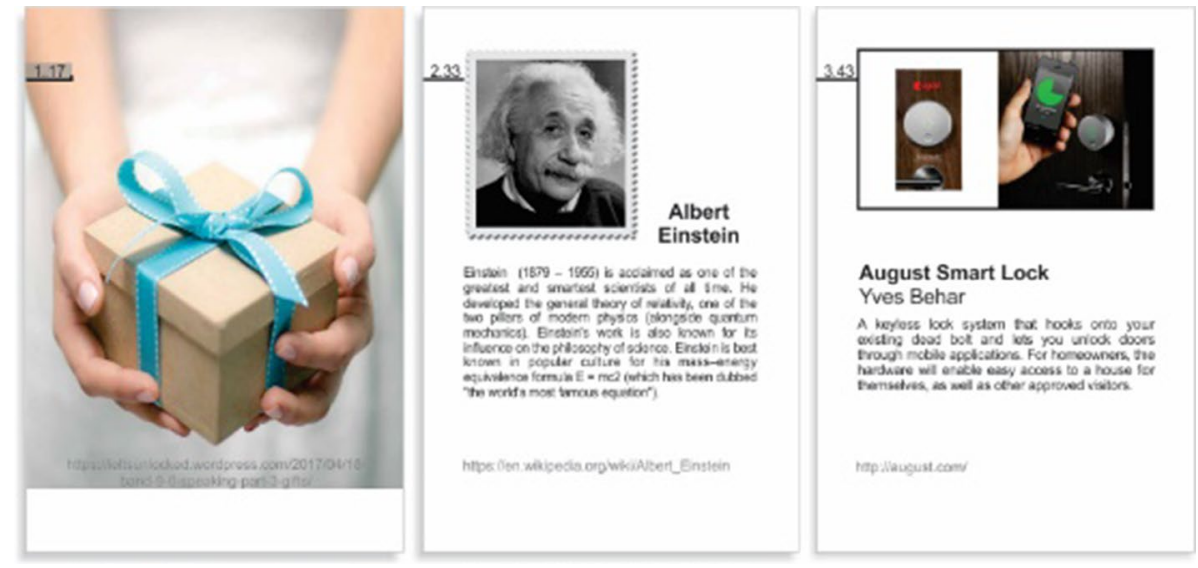

Fig. 3 Examples of picture cards (Size: $7 \times 10 \mathrm{~cm}$ ), three different types of cards including activity, persona, and product/service

The HuValue tool contains a value wheel (Fig. 1), 45 value words (Fig. 2), and 207 picture cards (Fig. 3). These elements are intended to bridge the gap between the abstract level of human values and the practical level of design. This tool is grounded on a comprehensive value framework for design (Kheirandish 2018). This framework was created and developed via research with various theoretical, empirical and design-based approaches to compile, classify and structure the existing value lists, including Rokeach (1973), Peterson and Seligman (2004), Schwartz (1992), and 10 more value lists from the last century (Kheirandish 2018). This value framework provides a holistic view of the values of different aspects of human life (Verkerk et al. 2015). In the HuValue tool, the value framework is illustrated in a circular form as the value wheel.

The Value wheel is a circle with nine value clusters. Each value cluster is introduced with an icon, a label, a mood board, a descriptive sentence, five key values, and some relevant terms. In the wheel, anyone can rank the value clusters in their order of importance to her/himself. Each value cluster has a 5-point scale: 'Extremely important', 'Very important', 'Important', 'Somewhat important', and 'Not important'. In addition to the words, colour saturation separates various levels of the scale: the highest saturation is for 'Extremely important' and the lowest saturation for 'Not important' (with three more in between).

The Value words are 45 two-sided cards with a value word on the front and its relevant value cluster at the back, based on empirical research for grouping the value words (Kheirandish 2018).

The Picture cards contain 207 cards of three different types: 66 activities, 66 personas, and 75 products/services. Every activity card contains a picture showing an activity or behaviour, without any description. At the bottom of each card, there is a space in which people can write their own interpretation. The persona and product cards are combinations of pictures and texts. Persona cards include well-known people from all over the world in different disciplines, without judgement about their positive or negative influence, in addition to some artificial personas. Product/service cards present a wide variety of products, services, and design concepts. 
Generally, the HuValue tool is a means of facilitating thinking about and discussing human values. This tool supports designers with simple but familiar materials during their design process to analyse everything (object/subject/situation) from a wide value point of view. This approach, referred to as the HuValue perspective, enables designers to be aware of and sensitive to human values and to consider various aspects of their topic and different types of values - even if they personally do not value them.

Being aware of the massive diversity in design processes (Dubberly 2005), the HuValue tool is intended not to be specified or limited within a fixed design process. For this reason, we proposed several applications based on common design activities (e.g., analysing the situation, defining the design goal, generating ideas, selecting a final idea, developing the concept, and realising and evaluating the final concept) that are fairly consistent across various design processes. In this respect, the tool can be applied for various purposes: the design challenge, the design goal, the context of use, and the user's needs, desires and requirements (Salem and Rauterberg 2004), all these elements can be studied from a value-centred point of view for a better understanding of the design situation. Human values can also be used, not only as a source of inspiration to expand the ideas, but also as a means of helping them to cluster and converge and can be applied as criteria for deciding on the final idea. Finally; the concepts thereby arrived at can be evaluated from a value perspective.

\section{Research design}

A quasi-experimental study (Snow 1974) was conducted to test and evaluate the HuValue tool in design education. For this, a group of undergraduate students from the Department of Industrial Design in an engineering-focused university was selected as participants. According to the literature (Shadish et al. 2002; Polit and Beck 2010), participants' cooperation is rarely perfect in studies with random samples. In fact, experiments almost never rely on random samples. We are aware that our sample is not representative of all design students worldwide and its deriving by the convenience method limits the generalisability of the findings.

In this study, the information was given to the participants via a workshop and group meetings; the data were collected via questionnaires and the students' final deliverables. The investigation was structured with the following research questions (RQx):

RQ1: Is the tool relevant and applicable to a design process?

RQ2: What is the role of training in the use of the HuValue tool?

\section{The relevancy of the HuValue tool for design}

To study how the HuValue tool can be applied in different design phases and how this could help students consider human values in their design, we supported randomly selected groups of students in the use of the tool over the whole of their design project. Six project groups received the HuValue and an introduction to its use. Six other project groups received, not only the tool and the introduction, but also more guidance over the semester about how to use it across different design phases. Four project groups without any support for human values were monitored as control groups. These control groups 
Fig. 4 Group meeting 1. A project group of TG is using the HuValue tool to discuss their design situation

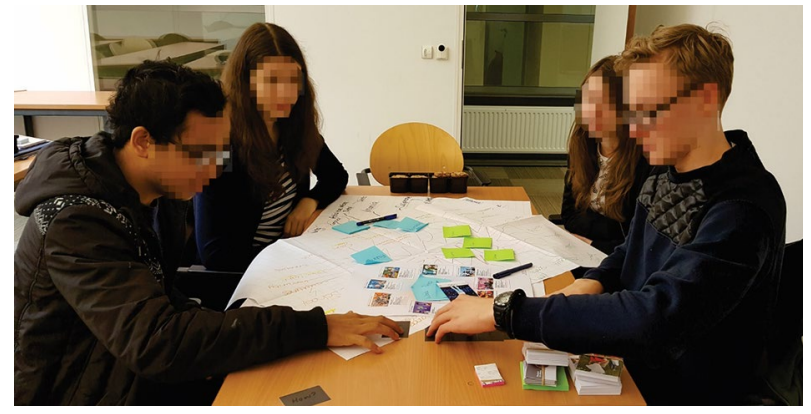

did not receive the tool. The plan was to look into all project groups' final designs to determine whether they used the HuValue tool in their design process, and if so, how and in which parts did they use the tool and for what purpose.

\section{Methodology}

The study was designed in the context of the first project of undergraduate design students (Project-1-Design). Students involved in this project, based on their interests, are asked to select one out of six project themes. Within every project theme, students were divided into groups of four and then sorted alphabetically by family name. At the end of the semester, every project group was to deliver a poster and a report. In the poster presentation, they were to introduce their final design concept; in the report, they were to describe their design process, their design iterations, their decisions, and relevant arguments as occurred during the project.

Our study was conducted in the context of Project-1-Design, from February until June 2017, with 192 students. To achieve the goal of the study, we selected randomly two project themes with an equal number of project groups as the participants ( 2 project themes $\times 8$ project groups $\times 4$ students $=64$ first-year design students), who were divided randomly into three categories:

- 'Trained Groups' (TG): Six project groups were selected by chance from two project themes: three groups from one theme and three groups from the other theme. They took part in an introductory workshop on human values and then, in further meetings, they were supported with step-by-step training on how to apply the tool in different parts of their project.

- 'Introduction Groups' (IG): Six project groups were selected by chance from two project themes: three groups from one theme and three groups from the other theme. They only took part in the human values introductory workshop.

- 'Control Groups' (CG): The other four project groups (two project groups from each theme), did not receive any specific information or support about human values.

To answer RQ1 and also RQ2, we carried out a workshop to introduce the HuValue tool and its applications in design to 12 project groups (TG and IG). During the workshop, at least three out of four students of each project group were present, and every student 
Table 2 Frequencies of project groups that used the HuValue tool

\begin{tabular}{lrrrrrr}
\hline & Total & \multicolumn{3}{l}{ HuValue tool use } \\
\cline { 3 - 7 } & & & \multicolumn{2}{l}{$\begin{array}{l}\text { Used the } \\
\text { tool }\end{array}$} & $\begin{array}{l}\text { Did not } \\
\text { use the } \\
\text { tool }\end{array}$ \\
\hline Trained groups (TG) & 6 & $37.5 \%$ & 6 & $37.5 \%$ & 0 & $0.0 \%$ \\
Introduction groups (IG) & 6 & $37.5 \%$ & 2 & $13.5 \%$ & 4 & $25.0 \%$ \\
Control groups (CG) & 4 & $25.0 \%$ & 1 & $6.3 \%$ & 3 & $18.7 \%$ \\
Total & 16 & $100.0 \%$ & 9 & $57.3 \%$ & 7 & $43.7 \%$ \\
\hline
\end{tabular}

received a set of the tool and guidance on how to use it for different purposes. Afterwards, the six TGs were guided step by step in group meetings to clarify their vision; identify potential user's needs, desires, and requirements; define their design goal and design challenge; generate creative and valuable ideas; and evaluate their final concepts. During the meetings, we did not provide the participants with any suggestions for using the tool in the realisation phase. A captured moment of one of these meetings is presented in Fig. 4.

At the end of the semester, each project group was expected to present their outcomes to the public (a week after they delivered their project reports). Here they described their design process and spoke about how the iterations contributed to their end results. After collecting the project group reports, to answer our first research question, 'Is the tool applicable in a design process?' we read and analysed their reports to find out whether they applied the tool in their project. If they did, we tried to find out in which phase and for what purpose the tool was used. Furthermore, we sought to understand how the tool had been used.

As this study was conducted in the context of a design project in an engineering-focused university, we had to follow the defined structure in this project: A design process with four phases of ideation, conceptualisation, realisation, and evaluation. In addition, in this programme at the start of the semester, students formulate their vision and goal in a personal development plan. Inevitably, in this study, we reported the tool applications and the design activities linked to the relevant design phases.

The two independent variables (IV) in this study were training and design phases, and the two dependent variables (DV) were tool use and value use:

- IV. Training: As explained above, all project groups in two randomly selected project themes were divided into three categories, namely, TG, IG, and CG, and were treated differently from one another.

- IV. Design phases: The project groups reported their design process in their final report via five divided phases: (1) defining vision, (2) ideation, (3) conceptualisation, (4) realisation, and (5) validation.

- DV. Tool use: Two levels $[1,2]$ of tool use in the project groups' reports were measured:

[1] 'Used the tool': Using the HuValue tool and/or its perspective was mentioned in the report.

[2] 'Did not use the tool': Using the tool and/or its perspective was not mentioned in the report. 
Table 3 Frequencies of tool usage and value usage vs design phases and training (Count of usage)

\begin{tabular}{|c|c|c|c|c|c|c|c|c|c|c|c|c|c|c|}
\hline \multirow[t]{3}{*}{ Tool usage } & \multirow[t]{3}{*}{ Value usage } & \multicolumn{12}{|c|}{ Design phases } & \multirow[t]{3}{*}{ Total } \\
\hline & & \multicolumn{3}{|c|}{ Vision } & \multicolumn{3}{|c|}{ Ideation } & \multicolumn{3}{|c|}{$\begin{array}{l}\text { Conceptuali- } \\
\text { sation }\end{array}$} & \multicolumn{3}{|c|}{ Validation } & \\
\hline & & TG & IG & $\mathrm{CG}$ & TG & IG & $\mathrm{CG}$ & TG & IG & $\mathrm{CG}$ & TG & IG & CG & \\
\hline \multirow[t]{2}{*}{ Did not use the tool } & Level 1 & 1 & 3 & 3 & 2 & 2 & 3 & - & 3 & 3 & 4 & 4 & 3 & 31 \\
\hline & Level 2 & - & 1 & 1 & - & 2 & - & - & 3 & 1 & 1 & 2 & 1 & 12 \\
\hline \multirow[t]{2}{*}{ Used the tool } & Level 3 & 3 & 1 & - & 2 & 2 & - & 3 & - & - & 1 & - & - & 12 \\
\hline & Level 4 & 2 & 1 & - & 2 & - & 1 & 3 & - & - & - & - & - & 9 \\
\hline
\end{tabular}

Table 4 Results of the statistical analysis of Pearson's Chi square test of independence for tool use and value use vs training and design phases

\begin{tabular}{llrl}
\hline Source & $d f$ & Chi $^{2}$ & Sig. (2-sided) \\
\hline Tool use * training & 2 & 20.436 & $.001 *$ \\
Tool use ${ }^{*}$ design phases & 3 & 7.017 & .071 \\
Value use * training & 6 & 23.886 & $.001 *$ \\
Value use * design phases & 9 & 8.237 & .510 \\
\hline
\end{tabular}

*Significant difference: $p<.05$

- DV. Value use: Four levels [1, 2, 3, 4] of value use in the project groups' reports were measured:

[1] 'Nothing about values'.

[2] 'Using value words without mentioning value': Value words were used explicitly, without identifying them as values.

[3] 'Using value words and the HuValue perspective without mentioning the tool': The workshop and/or the workshop leader's name, as well as 'values', were mentioned in the reports.

[4] 'Using value words, the HuValue perspective, and the HuValue tool': The tool was mentioned in the text and/or shown in photos.

\section{Results}

In the first step, we searched for the keyword 'value' in the reports of all 16 project groups (including 6 TG, 6 IG, and 4 CG) via the pdf search option. Except for two, the projects used the word 'value' regularly. However, the word 'value' was mostly used in its general meaning as 'the quality of being useful or important'; added value, value proposition, core value, intrinsic value, key value, and so forth were applied to designate 'positive features'. Then, we narrowed the search with some keywords such as 'human values', 'value tool', 'value workshop', and so forth. The results of this analysis, as presented in Table 2, indicate that the HuValue tool was used by TG, IG, and CG (number of project groups that used the tool). 
Table 5 Results of the cross-tabulation of significant results in the Chi square test of independence: Actual counts and expected counts

\begin{tabular}{|c|c|c|c|c|c|c|c|c|}
\hline \multirow[t]{2}{*}{ Training } & \multirow[t]{2}{*}{ Count } & \multirow[t]{2}{*}{ Total } & \multicolumn{2}{|c|}{ HuValue tool use } & \multicolumn{4}{|c|}{ Value use } \\
\hline & & & Used the tool & $\begin{array}{l}\text { Did not } \\
\text { use the } \\
\text { tool }\end{array}$ & Level 1 & Level 2 & Level 3 & Level 4 \\
\hline Trained groups (TG) & $\begin{array}{l}\text { Actual } \\
\text { Expected }^{\mathrm{a}}\end{array}$ & 24 & $\begin{array}{l}16 \\
(8)\end{array}$ & $\begin{array}{l}8 \\
(16)\end{array}$ & $\begin{array}{l}7 \\
(12)\end{array}$ & $\begin{array}{l}1 \\
(5)\end{array}$ & $\begin{array}{l}9 \\
(5)\end{array}$ & $\begin{array}{l}7 \\
(3)\end{array}$ \\
\hline $\begin{array}{l}\text { Introduction groups } \\
\text { (IG) }\end{array}$ & $\begin{array}{l}\text { Actual } \\
\text { Expected }\end{array}$ & 24 & $\begin{array}{l}4 \\
(8)\end{array}$ & $\begin{array}{l}20 \\
(16)\end{array}$ & $\begin{array}{l}12 \\
(12)\end{array}$ & $\begin{array}{l}8 \\
(5)\end{array}$ & $\begin{array}{l}3 \\
(5)\end{array}$ & $\begin{array}{l}1 \\
(3)\end{array}$ \\
\hline Control groups (CG) & $\begin{array}{l}\text { Actual } \\
\text { Expected }\end{array}$ & 16 & $\begin{array}{l}1 \\
(5)\end{array}$ & $\begin{array}{l}15 \\
(11)\end{array}$ & $\begin{array}{l}12 \\
(8)\end{array}$ & $\begin{array}{l}3 \\
(3)\end{array}$ & $\begin{array}{l}0 \\
(3)\end{array}$ & $\begin{array}{l}1 \\
(2)\end{array}$ \\
\hline Total & & 64 & 21 & 43 & 31 & 12 & 12 & 9 \\
\hline
\end{tabular}

${ }^{\text {a }}$ To calculate the expected value for each observed/actual value, multiply the marginal row and column totals for that cell and divide by the overall total: $E=\frac{\text { rowtotal } \times \text { column total }}{}$

Table 6 Frequencies of project groups reporting using human values for various purposes

\begin{tabular}{|c|c|c|c|c|c|c|c|c|}
\hline \multirow{2}{*}{$\begin{array}{l}\text { Application } \\
\text { Defining design goal }\end{array}$} & \multicolumn{2}{|l|}{ Total } & \multicolumn{2}{|c|}{$\begin{array}{l}\text { Trained } \\
\text { groups } \\
(\mathrm{TG})\end{array}$} & \multicolumn{2}{|c|}{$\begin{array}{l}\text { Introduc- } \\
\text { tion groups } \\
\text { (IG) }\end{array}$} & \multicolumn{2}{|c|}{$\begin{array}{l}\text { Control } \\
\text { groups }(\mathrm{CG})\end{array}$} \\
\hline & 7 & $26 \%$ & 5 & $18 \%$ & 2 & $7 \%$ & - & $0 \%$ \\
\hline Choosing final idea & 5 & $18 \%$ & 3 & $11 \%$ & 2 & $7 \%$ & - & $0 \%$ \\
\hline $\begin{array}{l}\text { Searching for what is important for the design } \\
\text { and make a list of values }\end{array}$ & 4 & $15 \%$ & 4 & $15 \%$ & - & $0 \%$ & - & $0 \%$ \\
\hline Discovering common value(s) of the group & 3 & $11 \%$ & 2 & $7 \%$ & 1 & $4 \%$ & - & $0 \%$ \\
\hline $\begin{array}{l}\text { Developing the concept to cover the intended } \\
\text { values }\end{array}$ & 3 & $11 \%$ & 3 & $11 \%$ & - & $0 \%$ & - & $0 \%$ \\
\hline $\begin{array}{l}\text { Being inspired by value words or related activi- } \\
\text { ties/products/personas }\end{array}$ & 3 & $11 \%$ & 1 & $4 \%$ & 1 & $4 \%$ & 1 & $4 \%$ \\
\hline Presenting intended values in a mood board & 1 & $4 \%$ & 1 & $4 \%$ & - & $0 \%$ & - & $0 \%$ \\
\hline Using intended values for user test & 1 & $4 \%$ & 1 & $4 \%$ & - & $0 \%$ & - & $0 \%$ \\
\hline Total & 27 & $100 \%$ & 20 & $74 \%$ & 6 & $22 \%$ & 1 & $4 \%$ \\
\hline
\end{tabular}

Lastly, since using the concept of value even without mentioning the terms 'value' or 'human values' was possible, we read the full reports and searched for value words. In this step, we were looking for the exact word or its other forms. For instance, for 'kindness', the phrase 'being kind' was also acceptable. After reviewing all reports, we measured two levels of tool use, and also four levels of value use in those reports. The frequency of tool usage and value usage in different design phases by three training groups of TG, IG and CG are presented in Table 3.

Furthermore, a statistical analysis of Pearson's Chi square test of independence was conducted on tool use and value use versus training and design phases, excluding the realisation phase, since any value use were not reported in this phase. The results of this test, as presented in Table 4, showed that two levels of tool use and also four levels of value use are significantly dependent on TG, IG, and CG; tool use versus training $\left(\mathrm{Chi}^{2}[2]=20.436\right.$, 
$p=0.001)$ and value use versus training $\left(\mathrm{Chi}^{2}[6]=23.886, p=0.001\right)$. The results did not suggest a significant interaction either between tool use and design phases or between value use and design phases. Further investigation with this test presented in Table 5 indicated that TG used the tool significantly more than expected. It also used values at the levels of three and four more than expected. IG used the tool less than expected: it used values at the levels of one and two more than expected. CG also used the tool less than expected: it used values in the first level more than expected.

As presented in Table 3, nine out of the 16 project groups mentioned using human values in their design process (six TG, two IG, and one CG); six reported using the HuValue tool in their design process (the tool was mentioned in the text and/or shown in photos), and three used the HuValue perspective in their design process (the workshop and/or the workshop leader's name, as well as 'values', were mentioned in the reports). Seven other project groups did not mention human values in their reports: five of them used value words unclearly (without identifying those words as values). Two other project groups did not mention anything about values. Moreover, the results indicated that using human values at levels 2, 3, and 4 of value use was reported most in the conceptualisation phase with 10 project groups. Both ideation and defining vision with nine project groups stood in second place, and validation with five groups was third. None of the groups used value words in the realisation phase.

To find out how project groups used human values in their design process, we went to the relevant parts in the reports, which mentioned using human values, and highlighted their purpose of use. Then we tried to find suitable labels for these. The results of this study, presented in Table 6, showed that the most popular purpose of using human values during their design process was 'Defining design goal' (26\%). This application was reported by seven different groups. The second and third popular applications of human values were 'Choosing final idea' (18\%), mentioned in five reports, and 'Searching for what is important for the design and make a list of values' (15\%), mentioned in four reports. The other applications were 'Discovering common value(s) of the group', 'Developing the concept to cover the intended values', 'Being inspired by values or related activities/products/personas', 'Presenting intended values in a mood-board' and 'Using intended values for user test'. These labels are representative of more or less similar methods that they described in the reports. For instance, two project groups explained that they assigned values to the generated ideas to find more relevant ideas for their intended values, one project group mentioned they clustered the generated ideas and assigned relevant values to them to find a more important idea, and the other project groups briefly mentioned that they used the intended values for choosing the final idea. So, we labelled them all as 'Choosing final idea'. One example of using the tool in a design project is presented in Fig. 5.

\section{Discussion and conclusion}

The main question in this part of our study was whether the tool is applicable in a design process. The results showed that nine out of the 16 project groups reported using the tool during their design, for different purposes.

All six project groups of TG, who received guidance for using the tool during the semester, used the tool in their design process. They used the tool for defining the vision, ideation, conceptualisation and also validation. In fact, they used the tool for the same purposes that we discussed during the workshop and group meetings. However, they mostly 

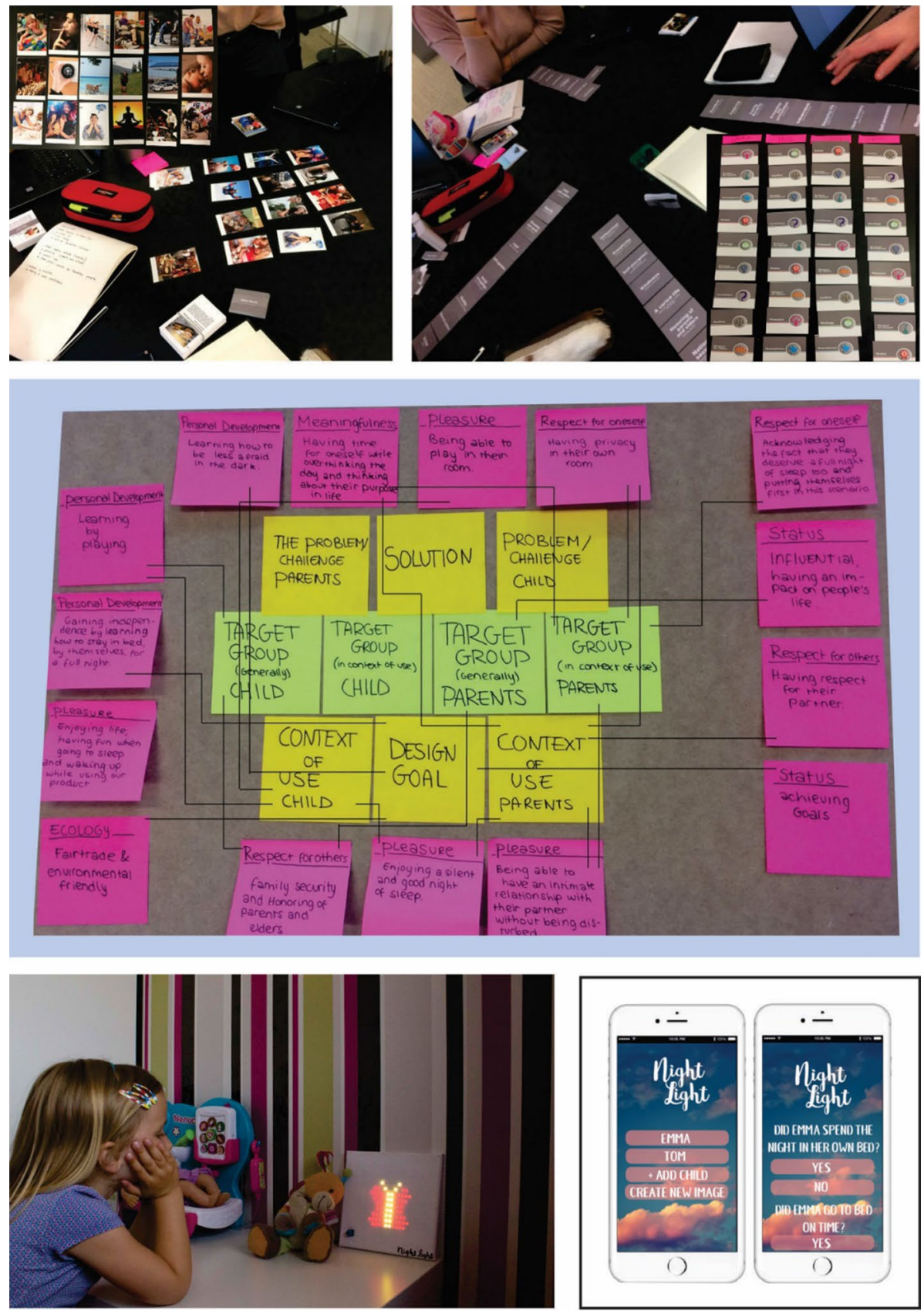

Fig. 5 An example of using the HuValue tool by a project group of TG: As they mentioned in their final report, they used the tool for defining the design goal, discovering common values for the team (Top right), brainstorming around picture cards and using them as inspiration (top left), searching for what is important for their design and making a list of values (middle). They introduced their final concept as following (bottom): NightLight is a tool to reward the child for staying in their own bed for the entire night (final report, Project Group D.1/TG). The highlighted values in this concept are: Personal development, Pleasure, Status, Respect for others, Carefulness, and Respect for oneself. The images were provided by the project group members in the final report 
preferred to follow their own personal and creative ways in its use. For instance, one project group used the tool for discovering common values for the team by ranking value words individually and then comparing them, and another project group discovered common values for the team by finding important values for each member and then clustering them and ranking the clusters.

As a whole, participants found the most important moments during the design process to use the tool: they used the tool for defining the vision and design goal, they saw it as a source of inspiration for finding ideas and also as a criterion for evaluating their idea, and they applied the tool to search for important values of the designer/user/design situation. Only in the validation phase was the tool not used as we expected, due to the lack of experience in prototyping and also in time management. In other words, in the validation phase, they did not have a functional prototype and/or enough time to do a proper user test.

As in TG, two project groups of IG (who were present in the workshop but not in the group meetings) used the tool in their design process. Those project groups applied the tool for defining the vision and ideation clearly, as we discussed in the workshop, but they did not go further. This indicates that training in various applications of the tool via project group meetings was important and helpful and, as the statistical analysis showed, using the tool was significantly dependent on this training.

Surprisingly, one project group of CG, who was supposed to have no access to the tool, received the tool from their friends in TG and used it. Although in an interview they mentioned that they did not have any information about the tool or its function and possible application(s) in design, they used the picture cards as inspiration in the ideation phase. This point showed that the tool functioned outside its goal (raising awareness about human values) and even without any training served as a useful toolkit in a design process. According to the results, presented in Table 3, some IG, and CG, who did not use the tool, used value words in the vision statement, ideation, conceptualisation, and validation phases-even though they did not mention them as 'values' explicitly. This shows that human values play an important role in these design phases, even if the student is not fully aware of that.

Moreover, beside using general terms of 'decision making' and 'value judgement' that widely are mentioned in technology and design education literature (e.g., Conway 1994; McLaren 1997; Pavlova 2005), this study, inspired by VSD (Friedman et al. 2017), VPD (Iversen et al. 2010), and VCD (Cockton 2005), provided practical details for applying the concept of human values in a design process.

\section{The role of training in the use of the HuValue tool}

To study the effectiveness of the tool, we used the results of the 16 selected project groups and assessed the design concepts they delivered to see whether training them with the tool was helpful in embodying more values in their design. In this evaluation, value enrichment was studied in two dimensions: the strength of the embedded values in the concepts and their diversity. To this end, we assessed the concepts and scored them from a value point of view for our nine value clusters. Next, regarding the strength of values, we tested the correlation of the scores with the categories of participants (TG, IG, and CG); and then for the diversity of values, we studied whether or not the number of addressed value clusters by TG, IG, and CG was statistically different. 


\section{Methodology}

For this part of our study, the same participants as in our previous section were investigated in the context of Project-1-Design with the 16 project groups $(16 \times 4=64$ first-year design students) as participants, in our three categories: TG, IG, and CG.

After collecting the project groups' deliverables, to answer RQ2 we assessed all projects and evaluated the design concepts from a value point of view. Concerning time and available facilities, in our study, we used students' design concepts instead of final prototypes to assess the students' output. Since design concepts were not ready to use or even test in real life, we could not use the real target groups of those design concepts for assessing them. Consequently, we used independent designers to assess the concepts, because we could expect them, as designers, to understand the concepts, their functions and intended behaviour from a poster, and to imagine themselves using those (not yet produced) products. The relevant value clusters in each concept were identified and rated on a 5-point rating scale from 'Not relevant' to 'Extremely relevant'. To detect bias in this assessment, we used three independent raters.

The independent variables (IV) in this study were training and value clusters in the design process; the dependent variables (DV) were nine value scores, total value score and value diversity of design concepts.

- IV. Training: The project groups were divided into three categories, the same as the previous section (see The relevancy of the HuValue tool for design).

- DV. Nine value scores: The design concepts were assessed in terms of our nine value clusters. All three raters were asked to assess the design concepts from a value point of view and for each concept to score the nine value clusters on a 5-point rating scale, 'Not relevant' $(=0)$, 'Somewhat relevant' $(=1)$, 'Relevant' $(=2)$, 'Very relevant' $(=3)$, and 'Extremely relevant' $(=4)$. In this way, every design concept received nine value scores (VS-X, range 0-4): VS-Carefulness, VS-Ecology, VS-Justice, VS-Meaningfulness, VS-Personal development, VS-Pleasure, VS-Respect for oneself, VS-Respect for others, and VS-Status.

- DV. Total value score: The sum of all nine single value scores for each concept made the total value score (VS-total, range 0-36).

- DV. Value diversity: To study the diversity of the embedded values in the design concepts, we summed the number of value clusters for each design concept that got scores above ' 0 ' to make up its value diversity. This dependent variable shows how many value clusters were addressed by each design concept (range 0-9).

\section{Rater reliability}

We asked three raters, with different ages, genders, and nationalities, but all with a design background, to do the assessment independently. The first rater $\left(\mathrm{R}_{1}\right)$ was 22 years old, male, Italian; the second rater $\left(\mathrm{R}_{2}\right)$ was 25 years old, female, Dutch; and the third rater $\left(\mathrm{R}_{3}\right)$ was 34 years old, female, Iranian. All three raters were asked to assess 16 design concepts. Each rater did the whole task individually and separately. For every concept, raters had a descriptive poster (the project group's poster, which was enriched with more information and pictures from their report) and a value wheel, and they were asked to follow step by 
Table 7 Cohen's kappa for three raters (taken two by two) in nine value scores

\begin{tabular}{|c|c|c|c|c|c|c|}
\hline \multirow[t]{2}{*}{ Variable } & \multicolumn{2}{|c|}{$\mathrm{R} 1$ \& R2 } & \multicolumn{2}{|c|}{$\mathrm{R} 1$ \& R3 } & \multicolumn{2}{|c|}{$\mathrm{R} 2 \& \mathrm{R} 3$} \\
\hline & $\kappa$ & Sig. & $\kappa$ & Sig. & $\kappa$ & Sig. \\
\hline VS-Carefulness & -.026 & .774 & -.004 & .950 & .127 & .169 \\
\hline VS-Ecology & .604 & .001 & .298 & .001 & .608 & .001 \\
\hline VS-Justice & .119 & .117 & .297 & .001 & -.104 & .340 \\
\hline VS-Meaningfulness & .285 & .009 & .379 & .001 & .155 & .021 \\
\hline VS-Personal development & .212 & .005 & .177 & .018 & .193 & .038 \\
\hline VS-Pleasure & .018 & .823 & .154 & .070 & .177 & .045 \\
\hline VS-Respect for oneself & .085 & .233 & .136 & .068 & .038 & .516 \\
\hline VS-Respect for others & .410 & .001 & .244 & .001 & .206 & .005 \\
\hline VS-Status & .025 & .825 & -.038 & .606 & .140 & .071 \\
\hline
\end{tabular}

$\kappa<0.00$ is Poor, $0.00-0.20$ is Slight, $0.21-0.40$ is Fair, $0.41-0.60$ is Moderate, $0.61-0.80$ is Substantial, $0.81-1.00$ is Almost Perfect (Landis and Koch 1977)

Bold Italics show the ratings that are used for further analysis (maximum kappa per value cluster)

Table 8 Descriptive analysis of nine value scores for TG, IG, and CG on a 5-point rating scale, 'Not relevant at all' $(=0)$, 'Somewhat relevant' $(=1)$, 'Relevant' $(=2)$, 'Very relevant' $(=3)$, and 'Extremely relevant' (=4)

\begin{tabular}{|c|c|c|c|c|c|c|c|c|c|}
\hline \multirow[t]{3}{*}{ Variable } & \multicolumn{9}{|c|}{ Training } \\
\hline & \multicolumn{3}{|c|}{ TG } & \multicolumn{3}{|c|}{ IG } & \multicolumn{3}{|c|}{$\mathrm{CG}$} \\
\hline & $N$ & $M$ & $S E$ & $N$ & $M$ & $S E$ & $N$ & $M$ & $S E$ \\
\hline VS-Carefulness & 6 & .50 & .13 & 6 & .17 & .11 & 4 & .00 & .00 \\
\hline VS-Ecology & 6 & .67 & .42 & 6 & .08 & .08 & 4 & .00 & .00 \\
\hline VS-Justice & 6 & .08 & .08 & 6 & .42 & .41 & 4 & .38 & .38 \\
\hline VS-Meaningfulness & 6 & .25 & .17 & 6 & .08 & .08 & 4 & .00 & .00 \\
\hline VS-Personal development & 6 & 1.25 & .60 & 6 & 1.50 & .55 & 4 & 1.38 & .55 \\
\hline VS-Pleasure & 6 & 1.25 & .33 & 6 & 1.00 & .26 & 4 & .63 & .38 \\
\hline VS-Respect for oneself & 6 & .92 & .51 & 6 & 1.08 & .35 & 4 & .25 & .25 \\
\hline VS-Respect for others & 6 & .58 & .30 & 6 & .50 & .32 & 4 & .63 & .38 \\
\hline VS-Status & 6 & .33 & .33 & 6 & .00 & .00 & 4 & .00 & .00 \\
\hline
\end{tabular}

step instructions. In the instructions, they were asked to take the poster, read the descriptive text of the concept, and underline any important word or phrase to introduce the concept. In addition, they were asked to try to understand the function(s) of the concept. To prevent confusion with their own imagination, they were asked to focus only on the exact features presented by students and their intended use and avoid adding any content of their own to the concept. They also were asked to identify the intended behaviour to which the 


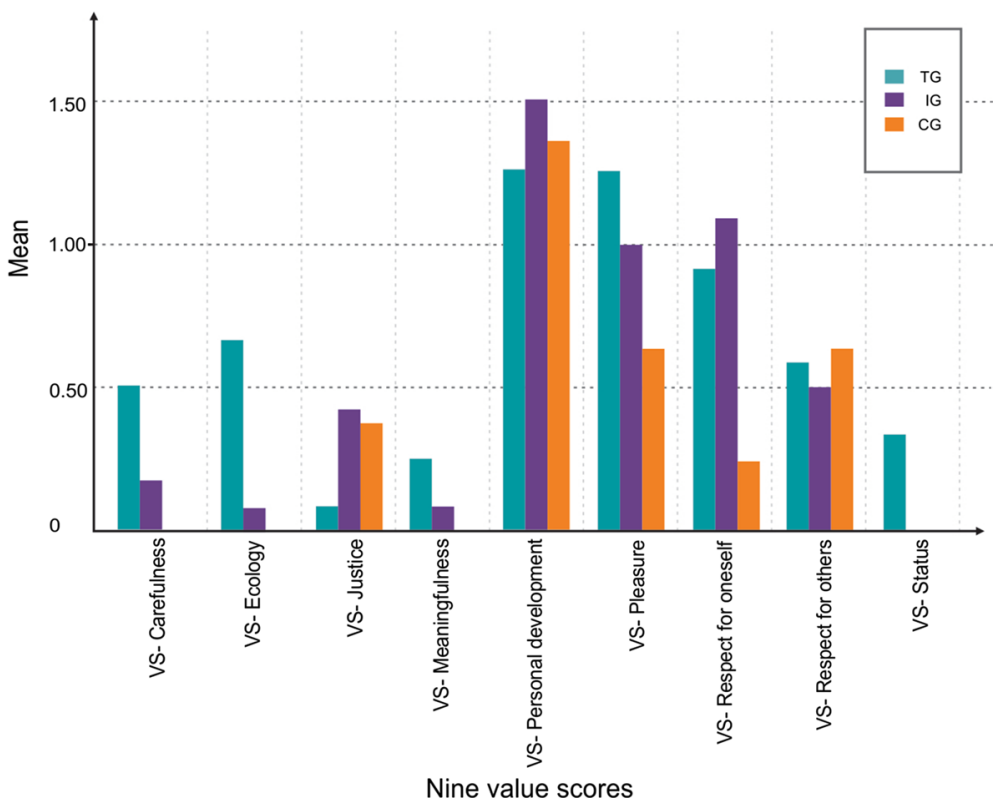

Fig. 6 Comparing the means of nine value scores for TG, IG, and CG on a 5-point rating scale, 'Not relevant at all' $(=0)$, 'Somewhat relevant' $(=1)$, 'Relevant' $(=2)$, 'Very relevant' $(=3)$, and 'Extremely relevant' (=4). VS-X, range 0-4. '0' scores are included in means

concept was applied. After imagining the concept in use and considering the underlined words/phrases, function(s), and also the intended behaviour of the user, each rater was instructed to take the value wheel, review all value clusters one by one to find the human values relevant to it, and circle them. They then scored all value clusters on a 5-point rating scale from 'Not relevant' to 'Extremely relevant' for each design concept (by asking themselves how much using the concept and executing the intended behaviour could be helpful for supporting and strengthening that intended human value in particular).

We assessed the reliability of the raters to reduce the risk of bias in the findings. To do so, we used the interrater reliability test of Cohen's kappa (к) to measure the interrater agreement in rating the relevant human values of the concepts. As this test works for two raters, we ran the test for raters two by two, $\left(R_{1} \& R_{2}, R_{1} \& R_{3}\right.$, and $\left.R_{2} \& R_{3}\right)$ for each value cluster (Table 7).

Afterwards, to find the most objective ratings, the results were compared, the most deviating rater in each value cluster was excluded, and the two more similar ratings merged. (For example, for VS-Carefulness, $\kappa$ for $\mathrm{R}_{1} \& \mathrm{R}_{2}$ and $\mathrm{R}_{1} \& \mathrm{R}_{3}$ are poor, and for $\mathrm{R}_{2} \& \mathrm{R}_{3}$ is slight. So, we used rating of $R_{2}$ and $R_{3}$ for the value cluster of Carefulness). The mean of these two individual ratings made a value score for each value cluster of every concept. This means every concept got nine value scores including VS-Carefulness, VS-Ecology, VS-Justice, VS-Meaningfulness, VS-Personal development, VS-Pleasure, VS-Respect for oneself, VS-Respect for others, and VS-Status. Table 8 and Fig. 6 present the nine value scores for TG, IG, and CG. 
Table 9 One-way ANOVA of total value score (VS-total) and training

\begin{tabular}{|c|c|c|c|c|c|c|c|c|c|c|c|c|}
\hline \multirow[t]{3}{*}{ Variable } & \multicolumn{9}{|c|}{ Training } & \multirow[t]{3}{*}{$d f$} & \multirow[t]{3}{*}{$F$} & \multirow[t]{3}{*}{ Sig. } \\
\hline & \multicolumn{3}{|c|}{ TG } & \multicolumn{3}{|l|}{$\mathrm{IG}$} & \multicolumn{3}{|c|}{$\mathrm{CG}$} & & & \\
\hline & $N$ & $M$ & $S E$ & $N$ & $M$ & $S E$ & $N$ & $M$ & $S E$ & & & \\
\hline VS-total & 6 & 5.83 & .63 & 6 & 4.83 & .57 & 4 & 3.25 & .48 & 2.15 & 4.265 & $.038^{*}$ \\
\hline
\end{tabular}

*Significant difference: $p<.05$

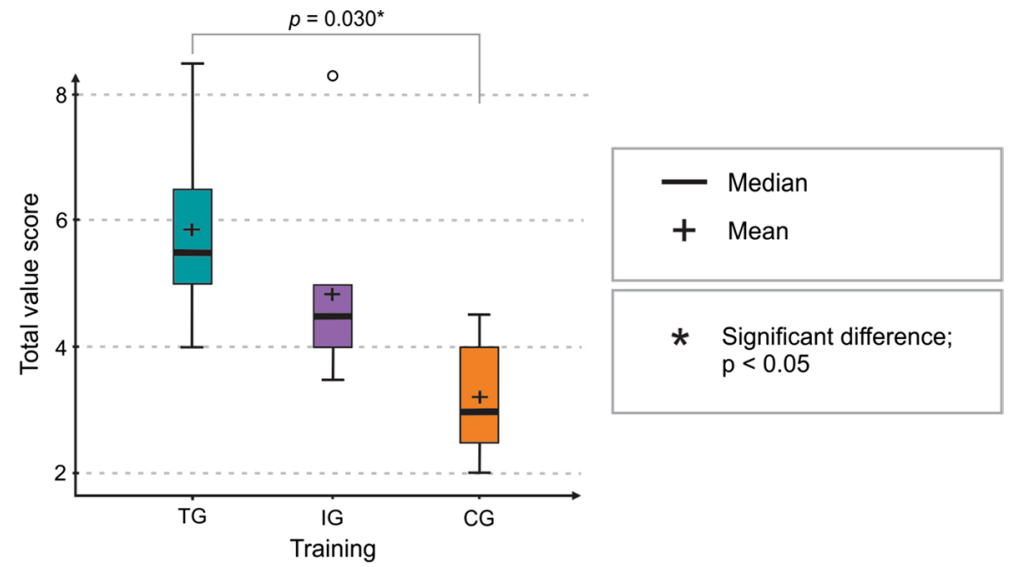

Fig. 7 Descriptive analysis of total value score for TG, IG, and CG. TG had a statistically significantly higher total value score than $\mathrm{CG}$

\section{Results}

In this part, first, we present the nine value scores that are the results of the concept assessment after excluding the most deviating rater in each value cluster. Then, we present the results of the statistical analysis of the dependent variables, total value score and value diversity.

The results presented in Table 8 indicate that TG, IG, and CG obtained different nine value scores $(V S-X)$. This, as illustrated in Fig. 6, shows that the means of VS-Meaningfulness, VS-Ecology, VS-Pleasure, VS-Status, and VS-Carefulness for TG were higher than IG and CG; the means of VS-Personal development and VS-Respect for oneself for IG were higher than for TG and CG; and the means of VS-Respect for others for CG was the highest. 


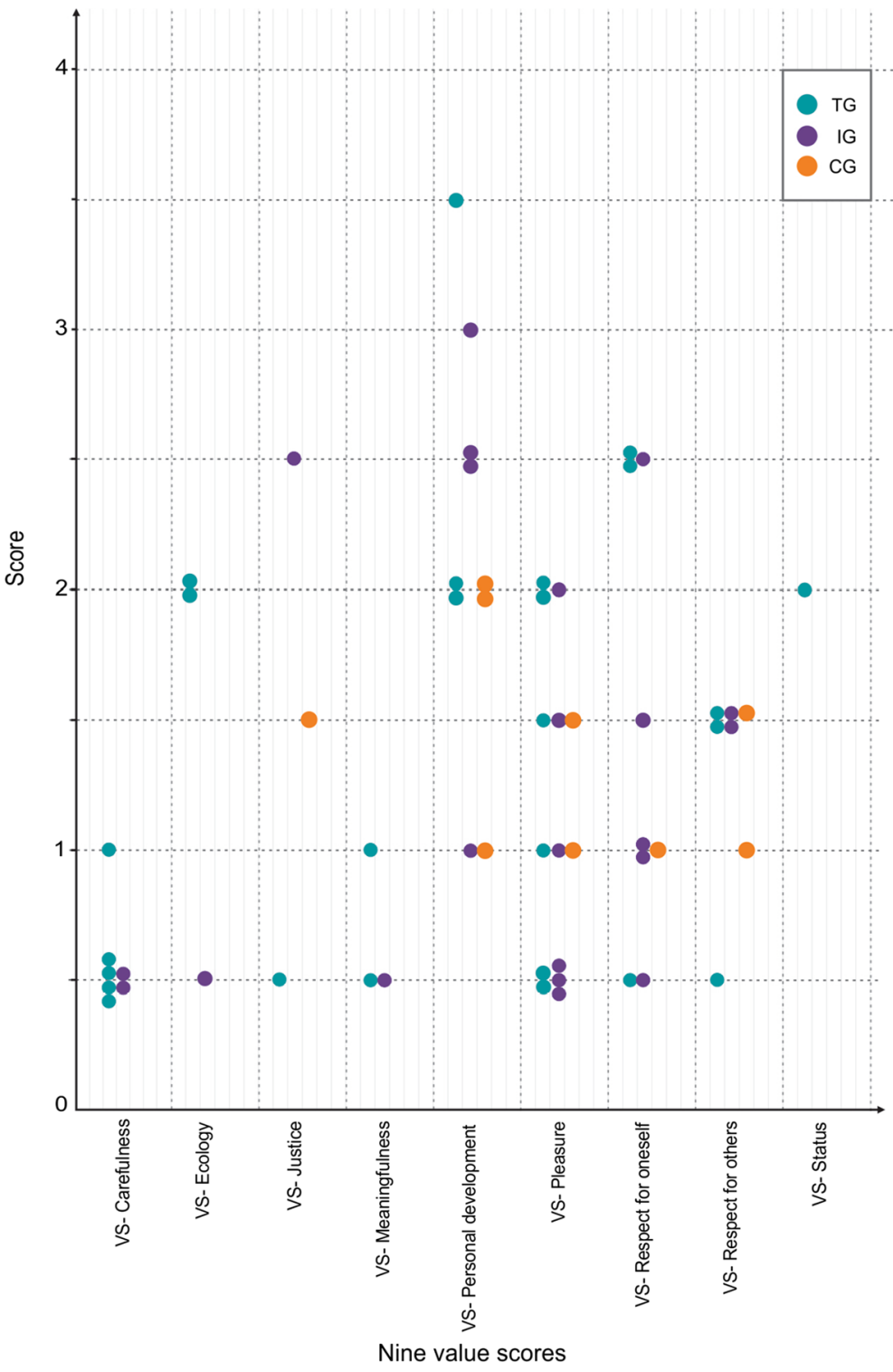

Fig. 8 Value diversity for TG, IG, and CG: Each dot represents a value score above '0'. The value scores equal to ' 0 ' are not presented here. $V S-X$, range $0-4$

\section{Total value score}

To investigate the strength of the values embedded in the concepts, we defined the dependent variable total value score (VS-total). To test whether there is a statistical difference between the means of the total value scores for TG, IG, and CG, we used a one-way ANOVA of total value score and training. The results, as presented in Table 9, indicate that the difference between the means of the total value scores for TG, IG, and 
Table 10 One-way ANOVA of value diversity and training

\begin{tabular}{|c|c|c|c|c|c|c|c|c|c|c|c|c|}
\hline \multirow[t]{3}{*}{ Variable } & \multicolumn{9}{|c|}{ Training } & \multirow[t]{3}{*}{$d f$} & \multirow[t]{3}{*}{$\mathrm{F}$} & \multirow[t]{3}{*}{ Sig. } \\
\hline & \multicolumn{3}{|c|}{ TG } & \multicolumn{3}{|c|}{ IG } & \multicolumn{3}{|c|}{ CG } & & & \\
\hline & $\mathrm{N}$ & M & SE & $\mathrm{N}$ & M & SE & $\mathrm{N}$ & M & SE & & & \\
\hline Value diversity & 6 & 4.33 & .56 & 6 & 3.67 & .62 & 4 & 2.25 & .63 & 2.15 & 2.691 & .105 \\
\hline
\end{tabular}

*Significant difference: $p<.05$

CG is statistically significant, $F(2,15)=4.265, p=.038$. Furthermore, applying the post hoc test of Tukey reveals that TG $(M=5.83, S E=0.63)$ had a statistically significantly higher value score compared to CG $(M=3.25, S E=0.48),(p=.030)$. Nonetheless, the total value score of IG was not significantly different from TG and CG. The descriptive analysis of the total value scores for TG, IG, and CG is shown in Fig. 7.

\section{Value diversity}

To study the diversity of the values embedded in the design concepts, we defined the dependent variable value diversity. This variable shows how many value clusters were addressed by each design concept. A comparison of the number of value scores above ' 0 ' in each value cluster, as presented in Fig. 8, indicates that the value clusters 'Pleasure', 'Personal development', and 'Respect for others' were addressed in the design concepts more frequently. But the value clusters 'Meaningfulness', 'Status', and 'Ecology' were addressed only in few design concepts.

Furthermore, we used a one-way ANOVA of the value diversity and training to test whether there is a statistical difference between the means of value diversity for TG, IG, and CG. As presented in Table 10, this test did not suggest any significant differences, but the trend of means is similar to total value score.

\section{Discussion and conclusion}

We investigated the role of training in the use of the HuValue tool with the two variables of total value score and value diversity.

In the total value score, the test indicated a significant difference between TG, IG, and $\mathrm{CG}$, in which the total value score of TG was significantly higher than CG. However, as presented in Fig. 6, the means of the nine value scores $(V S-X)$ were generally lower than 1.50. Indeed, this result is lower than our expectation, although the highest scores in different value clusters gained by TG and IG (see Fig. 8); still, there is room for strengthening the addressed values.

In value diversity, the results did not suggest any significant difference between TG, IG, and CG. To check whether this non-significant result was due to a lack of statistical power, we conducted a post hoc power analysis with the program G*Power (Faul et al. 2007). This test revealed that, on the basis of the mean, between-groups comparison effect size observed in the present study $(d=.52)$, an $N$ of approximately 39 would be needed for a power $(1-\beta)$ set at 0.80 and $\alpha=05$. So, in the present study with the sample size of 16 , we could not conclude that there was a difference between the categories. Although all three means indicated 
the direction of our hypothesis, a simple counting of the value scores above ' 0 ' (Fig. 8) showed that Control Groups (CG) of the two project themes addressed merely 'Personal development', 'Pleasure', 'Respect for others', 'Justice', and 'Respect for oneself'. But TG and IG, which had been supported with the HuValue tool, almost covered all value clusters on these same themes. This result was consistent with the idea that, regardless of the project theme, project groups without any specific training mostly focused on pleasure and personal development. Yet values such as meaningfulness and carefulness usually remained out of attention. In this respect, the HuValue tool seemed very helpful for widening the students' view on diverse aspects of life and for encouraging them to use different types of values.

\section{General conclusion}

In this study, the first research question asked whether the tool was relevant to a design process. The findings illustrated that the answer was 'yes'. As the study evidenced, the tool was used for defining the vision, ideation, conceptualisation, and validation of the design idea. The study also showed that the tool was capable of being used for different purposes. According to the results, it can be used for defining the vision and design goal. It can be seen as a source of inspiration for finding ideas and also as criteria for evaluating them in any design iterations. The tool is applicable to searching for important values of the designer/user/design situation and providing materials to visualise them. These applications are more or less the same as what we proposed for applying the tool. However, each design student can use them in her/his own creative way.

The second research question of this study inquired about the role of training in the use of the HuValue tool for enriching design concepts with human values. In this study, value enrichment was considered in terms of the strength of the embedded values and also their diversity: Firstly, the results indicated a significant effect of training on value score, in which total value score of TG was significantly higher than CG. This means the project groups that had been supported with the HuValue tool addressed stronger (more identifiable and recognisable) human values in their design concepts compared to the control groups. Secondly, the results did not indicate a significant effect of training on value diversity, probably due to a lack of statistical power. Further, a counting of the value scores above ' 0 ' for the two main project themes showed that the four value clusters, 'Meaningfulness', 'Carefulness', 'Ecology', and 'Status' were not addressed with CG, whereas TG addressed all nine value clusters. These results show that the tool can be helpful for increasing the diversity of the values embedded in the design concepts, since the participants who received specific training about using the HuValue tool addressed more diverse human values compared to the control groups with no specific support about human values.

All in all, our study provides sufficient evidence that the tool is applicable and effective for embedding human values in design education. This finding shows that widening design students' view in terms of human values and facilitating using this concept in a design process could be helpful for enriching their design concepts with human values. The convenience sample of this study was not representative of all design students worldwide, however-thereby limiting interpretation of the results. It is thus highly recommended that future studies include students from multiple institutions.

The HuValue tool provides tangible materials for investigating all elements (object/subject/situation) of the design process from a human value perspective. Due to the flexibility of its components, this function can be fulfilled in many different ways-not only for raising 
design students' awareness about human values but also for uncovering the human values behind needs, goals, motivations, and actions. Although the concept of human values is borrowed from philosophy and the social sciences, by revealing the place of this concept in every design discussion, the HuValue tool presents human values as an original term in design. This tool, unlike Value Sensitive Design, does not bring human values forward as a moral and ethical concern, but rather as an essential aspect of design discussions and practice.

In our future study, we plan to digitalise HuValue and make it available online for design students from all over the world. By introducing the tool widely, we expect to receive more feedback, comments, and even help for its further development. Also, we intend to test the tool in professional design projects with senior designers, use it for embedding specific values in products, and investigate the influence of using those products on real users.

Acknowledgements We thank our colleagues Jan Rouvroye, Lenneke Kuijer, and David McCallum, who, as the project coaches, gave us the opportunity of conducting our experimental study in the context of Project1-Design. We would also like to express our gratitude to all the students participating in this study: Firstyear design students in design themes of It Did It Again and Dreams Come to Life at the Industrial Design Department, Eindhoven University of Technology, in Semester B: February-June 2017.

Open Access This article is distributed under the terms of the Creative Commons Attribution 4.0 International License (http://creativecommons.org/licenses/by/4.0/), which permits unrestricted use, distribution, and reproduction in any medium, provided you give appropriate credit to the original author(s) and the source, provide a link to the Creative Commons license, and indicate if changes were made.

\section{References}

Barlex, D. (1993). The Nuffield approach to values in design and technology. Design and Technology Teaching, 26(1), 42-45.

Biffl, S., Aurum, A., Boehm, B., Erdogmus, H., \& Grünbacher, P. (2006). Value-based software engineering. Berlin: Springer.

Borning, A., \& Muller, M. (2012). Next steps for value sensitive design. In Proceedings of the SIGCHI conference on human factors in computing systems 2012 (pp. 1125-1134). Austin, TX: ACM.

Boztepe, S. (2003). The notion of value and design. In H. Aoki (Ed.), In Proceedings of the Asian design international conference, 1 [CD]. Tsukuba, Japan.

Boztepe, S. (2007a). Toward a framework of product development for global markets: A user-value-based approach. Design Studies, 28, 513-533.

Boztepe, S. (2007b). User value: Competing theories and models. International Journal of Design, 1(2), $55-63$.

Breckon, A. (1998). National curriculum review in design and technology for the year 2000. The Journal of Design and Technology Education, 3(2), 101-105.

Cockton, G. (2004). Value-centred HCI. In Proceedings of the 3rd Nordic conference on human-computer interaction (pp. 149-160). Tampere, Finland: ACM.

Cockton, G. (2005). A development framework for value-centred design. In Proceedings of CHI 2005 extended abstracts on human factors in computing systems (pp. 1292-1295). Portland, OR: ACM.

Cockton, G. (2006). Designing worth is worth designing. In Proceedings of the 4th Nordic conference on human-computer interaction: Changing roles (pp. 165-174). Oslo, Norway: ACM.

Coles, R., \& Norman, E. (2005). An exploration of the role values play in design decision-making. International Journal of Technology and Design Education, 15(2), 155-171.

Collopy, P. D., \& Hollingsworth, P. (2011). Value-driven design. Journal of Aircraft, 48, 749-759.

Conway, R. (1994). Values in technology education. International Journal of Technology and Design Education, 4(1), 109-116.

Conway, R., \& Riggs, A. (1994). Valuing in technology. In F. Banks (Ed.), Teaching technology (pp. 227237). London: Routledge.

Cummings, M. L. (2006). Integrating ethics in design through the value-sensitive design approach. Science and Engineering Ethics, 12, 701-715. 
Dakers, J. R. (2005). The hegemonic behaviorist cycle. International Journal of Technology and Design Education, 15(2), 111-126.

de Vries, M. (2005). The nature of technological knowledge: Philosophical reflections and educational consequences. International Journal of Technology and Design Education, 15(2), 149-154.

Detweiler, C. A. (2016). Accounting for values in design. Unpublished doctoral dissertation, Delft University of Technology, Delft, The Netherlands.

Dorrestijn, S. (2012). The design of our own lives: Technical mediation and subjectivation after Foucault. Unpublished doctoral dissertation, Univesity of Twente, Enschede, The Netherlands.

Dubberly, H. (2005). How do you design? A compendium of models. Retrieved 17 May 2018 from http:// www.dubberly.com/articles/how-do-you-design.html.

Elshof, L. (2005). Teacher's interpretation of sustainable development. International Journal of Technology and Design Education, 15(2), 173-186.

Faul, F., Erdfelder, E., Lang, A.-G., \& Buchner, A. (2007). G*Power 3: A flexible statistical power analysis program for the social, behavioral, and biomedical sciences. Behavior Research Methods, 39(2), $175-191$.

Friedman, B., Hendry, D. G., \& Borning, A. (2017). A survey of value sensitive design methods. Foundations and Trends ${ }^{\circledR}$ in Human-Computer Interaction, 11(2), 63-125.

Friedman, B., \& Kahn, J. P. (2003). Human values, ethics, and design. In S. Andrew, J. Jacko, \& J. Jacko (Eds.), The human-computer interaction handbook (pp. 1177-1201). Boca Raton, FL: CRC.

Friedman, B., Kahn, J. P., Borning, A., \& Huldtgren, A. (2013). Value sensitive design and information systems. In N. Doorn, D. Schuurbiers, I. van de Poel, \& M. Gorman (Eds.), Early engagement and new technologies: Opening up the laboratory (Vol. 16, pp. 55-95). Dordrecht: Springer.

Halloran, J., Hornecker, E., Stringer, M., Harris, E., \& Fitzpatrick, G. (2009). The value of values: Resourcing co-design of ubiquitous computing. CoDesign, 5, 245-273.

Holdsworth, I., \& Conway, B. (1999). Investigating values in secondary design and technology education. The Journal of Design and Technology Education, 4, 205-214.

Iversen, O. S., Halskov, K., \& Leong, T. (2010). Rekindling values in participatory design. In Proceedings of the 11th Biennial participatory design conference (pp. 91-100). Sydney, Australia: ACM.

Iversen, O. S., Halskov, K., \& Leong, T. W. (2012a). Value-led participatory design. Co Design: International Journal of CoCreation in Design and the Arts, 8(2-3), 87-105.

Iversen, O. S., \& Leong, T. W. (2012). Values-led participatory design: mediating the emergence of values. In Proceedings of the 7th Nordic conference on human-computer interaction: Making sense through design (pp. 468-477). Copenhagen, Denmark: ACM.

Iversen, O. S., Loeng, T., Wright, P., Gregory, J., \& Bowker, G. (2012b). Working with human values in design. In Proceedings of the 12th participatory design conference: Exploratory papers, workshop descriptions, industry cases. 2 (pp. 143-144). Roskilde, Denmark: ACM.

Järvinen, E.-M., \& Rasinen, A. (2015). Implementing technology education in Finnish general education schools: Studying the cross-curricular theme 'Human being and technology'. International Journal of Technology and Design Education, 25(1), 67-84.

Kheirandish, S. (2018). HuValue-A tool to enrich design concepts with human values. Unpublished doctoral dissertation, Eindhoven University of Technology, Eindhoven, The Netherlands.

Knobel, C., \& Bowker, G. (2011). Values in design. Communications of the ACM, 54(7), 26-28.

Kujala, S., \& Väänänen-Vainio-Mattila, K. (2008). Value of information systems and products: Understanding the users' perspective and values. JITTA: Journal of Information Technology Theory and Application, 9(4), 23-39.

Landis, J. R., \& Koch, G. (1977). The measurement of observer agreement for categorical data. Biometrics, 33(1), 159-174.

Layton, D. (1991). Aspects of national curriculum: Design and technology. New York, NY: NCC.

Leong, T. W., \& Iversen, O. (2015). Values-led participatory design as a pursuit of meaningful alternatives. In Proceedings of the annual meeting of the australian special interest group for computer human interaction (pp. 314-323). Parkville, VIC, Australia: ACM.

Lockton, D. (2013). Design with intent: a design pattern toolkit for environmental and social behaviour change. Unpublished doctoral dissertation, Brunel University, London, UK.

Lucero, A., Dalsgaard, P., Halskov, K., \& Buur, J. (2016). Designing with cards. In P. Markopoulos, J. Martens, J. Malins, K. Coninx, \& A. Liapis (Eds.), Collaboration in creative design (pp. 75-95). Berlin: Springer.

Manders-Huits, N. (2011). What values in design? The challenge of incorporating moral values into design. Science and Engineering Ethics, 17, 271-287.

Martin, M. (2002). Values and attitudes in design and technology. In S. Sayers, J. Morley, \& B. Barnes (Eds.), Issues in design and technology teaching (pp. 208-223). London: Routledge. 
McLaren, S. (1997). Value judgements: Evaluating design-A Scottish perspective on a global issue. International Journal of Technology and Design Education, 3, 259-278.

Middleton, H. (2005). Creative thinking, values and design and technology education. International Journal of Technology and Design Education, 15(1), 61-71.

Mora, S., Asheim, J., Kjøllesdal, A., \& Divitini, M. (2016). Tiles Cards: A card-based design game for smart objects ecosystems. In Proceedings of the first international workshop on smart ecosystems creation by visual design (pp. 19-24). Bari, Italy: SERVE@ AVI.

Nackmayr, J., Thomson, R., Longstaff, T., \& Mcmicking, J. (2016). High Value Design. Retrieved 9 January 2018, from https://www.rolandberger.com/en/Publications/pub_high_value_design.html.

O’Neill, M. G., Yue, H., Nag, S., Grogan, P., \& de Weck, O. (2010). Comparing and optimizing the DARPA system F6 program value-centric design methodologies. In Proceedings of the AIAA space conference. Anaheim, California: AIAA SPACE Forum. https://doi.org/10.2514/6.2010-8828.

Onselen, L. V., \& Valkenburg, R. (2015). Personal values as a catalyst for meaningful innovations: Supporting young designers in collaborative practice. In Proceedings of the 20th international conference on engineering design (ICED 15), 1: Design for Life (pp. 547-556). Milan, Italy.

Oosterlaken, I. (2015). Applying value sensitive design (VSD) to wind turbines and wind parks: An exploration. Science and Engineering Ethics, 21, 359-379.

Pavlova, M. (2005). Knowledge and values in technology education. International Journal of Technology and Design Education, 15(2), 127-147.

Pavlova, M. (2009). Conceptualisation of technology education within the paradigm of sustainable development. International Journal of Technology and Design Education, 19(2), 109-132.

Peterson, C., \& Seligman, M. (2004). Character strengths and virtues: A handbook and classification (Vol. 1). Oxford: Oxford University Press.

Polit, D. F., \& Beck, C. (2010). Generalization in quantitative and qualitative research: Myths and strategies. International Journal of Nursing Studies, 47(11), 1451-1458.

Prime, G. M. (1993). Values in technology: Approaches to learning. Design and Technology Teaching, 26(1), 30-36.

Rekus, J. (1991). Teaching technology with a focus on moral education. International Journal of Technology and Design Education, 2(2), 41-46.

Riggs, A., \& Conway, R. (1991). Values and technology education. Design \& Technology Teaching, 24(1), 31-33.

Rokeach, M. (1973). The nature of human values. New York, NY: The Free Press.

Ross, P. (2008). Ethics and aesthetics in intelligent product and system design. Unpublished doctoral dissertation, Eindhoven University of Technology, Eindhoven, The Netherlands.

Saariluoma, P., Cañas, J., \& Leikas, J. (2016). Designing for life. London: Palgrave Macmillan.

Salem, B., \& Rauterberg, M. (2004). Multiple user profile merging (MUPE): Key challenges for environment awareness. In P. Markopoulos, B. Eggen, E. Aarts, \& J. Crowley (Eds.), Ambient Intelligence: Second European Symposium-EUSAI (pp. 196-206). Heidelberg: Springer.

Schwartz, S. (1992). Universals in the content and structure of values: Theoretical advances and empirical tests in 20 countries. Advances in Experimental Social Psychology, 25, 1-65.

Shadish, W., Cook, T., \& Campbell, D. (2002). Experimental and quasi-experimental designs for generalized causal inference. Boston, MA: Houghton Mifflin.

Simon, H. A. (1996). The sciences of the artificial. Cambridge: MIT Press.

Snow, R. E. (1974). Representative and quasi-representative designs for research on teaching. Review of Educational Research, 44, 265-291.

Stanton, N. A., \& Baber, C. (1998). Designing for consumers. Applied Ergonomics, 29(1), 1-3.

Steen, M., \& van de Poel, I. (2012). Making values explicit during the design process. IEEE Technology and Society Magazine, 31(4), 63-72.

TUDelft Design for Values. (2018). Design for Values. Retrieved 8 January 2018, from http://designforv alues.tudelft.nl/.

Tungaraza, F., \& Sutherland, M. (2005). Capturing the minds of a lost and lonely generation. International Journal of Technology and Design Education, 15(2), 187-198.

Value Based Design. (2018). Retrieved 8 January 2018 from http://www.valuebaseddesign.com.

Value (n.d.). In The Oxford online dictionary. Retrieved from https://www.oxfordlearnersdictionaries.com/ definition/english/value_1?q=value.

Verbeek, P. P. (2005). What things do: Philosophical reflections on technology, agency, and design. (R. P. Crease, Trans.). University Park, PA: Penn State Press.

Verkerk, M. J., Hoogland, J., Van der Stoep, J., \& de Vries, M. J. (2015). Philosophy of technology: An introduction for technology and business students. London: Routledge. 
Wölfel, C., \& Merritt, T. (2013). Method card design dimensions: A survey of card-based design tools. In Proceedings of IFIP conference on human-computer interaction (pp. 479-486). Berlin: Springer.

Publisher's Note Springer Nature remains neutral with regard to jurisdictional claims in published maps and institutional affiliations. 